\title{
PENENTUAN KOEFISIEN ABSORBSI BUNYI DAN IMPEDANSI AKUSTIK DARI SERAT ALAM ECENG GONDOK (EICHHORNIA CRASSIPES) DENGAN MENGGUNAKAN METODE TABUNG
}

\author{
Vonny Febrita, Elvaswer \\ Jurusan Fisika FMIPA Universitas Andalas \\ Kampus Unand, Limau Manis, Padang, 25163 \\ e-mail:vonyfebrita@gmail.com
}

\begin{abstract}
ABSTRAK
Telah dilakukan penelitian untuk menentukan nilai koefisien absorbsi bunyi dan impedansi akustik dengan menggunakan metode tabung. Material akustik dibuat menggunakan serat eceng gondok dan matriks PVAc dengan ketebalan yang sama yaitu $0,8 \mathrm{~cm}$. Pengukuran dilakukan pada frekuensi $400 \mathrm{~Hz}, 800 \mathrm{~Hz}, 1600 \mathrm{~Hz}, 3200 \mathrm{~Hz}$ dan $6400 \mathrm{~Hz}$. Koefisien absorbsi bunyi tertinggi dengan nilai 0,98 pada frekuensi $6400 \mathrm{~Hz}$ adalah sampel 4 dengan komposisi serat 35,0 g dan matriks 27,5 g, sedangkan koefisien absorbsi bunyi terendah dengan nilai 0,16 pada frekuensi $1600 \mathrm{~Hz}$ adalah sampel 2 dengan komposisi serat $30 \mathrm{~g}$ dan matriks 32,5 g. Nilai impedansi tertinggi yaitu $0,9869 \mathrm{~kg} / \mathrm{m}^{2} \mathrm{~s}$, sedangkan nilai impedansi terendah $0,8825 \mathrm{~kg} / \mathrm{m}^{2} \mathrm{~s}$. Nilai densitas tertinggi yaitu $0,91 \mathrm{~g} / \mathrm{cm}^{3}$, sedangkan nilai densitas terendah $0,67 \mathrm{~g} / \mathrm{cm}^{3}$. Serat eceng gondok dapat digunakan untuk mengendalikan kebisingan karena mampu menyerap bunyi pada frekuensi rendah dan tinggi.
\end{abstract}

Kata kunci: serat, eceng gondok, metode tabung, absorbsi, impedansi

\section{PENDAHULUAN}

Kebisingan adalah bunyi atau suara yang tidak diinginkan sehingga dapat menimbukan gangguan kesehatan dan kenyamanan lingkungan. Upaya yang dapat dilakukan untuk mengendalikan kebisingan adalah dengan membuat material akustik yang efektif dalam menyerap bunyi ( $\mathrm{Na} \mathrm{Y}$ dan Cho, 2007).

Komposit didefinisikan sebagai material yang terdiri dari dua atau lebih material penyusun yang berbeda yaitu serat dan matriks. Serat adalah suatu bahan berupa potongan yang membentuk jaringan yang utuh. Serat yang digunakan dalam penelitian ini adalah serat alam eceng gondok. Matriks adalah suatu polimer karet sintetik digunakan sebagai pengikat serat. Matriks yang digunakan adalah matriks PVAc (Gibson, 1984).

Serat eceng gondok memiliki kandungan selulosa yang tinggi yaitu sebesar $64,51 \%$, hemiselulosa $33 \%$, lignin $7,69 \%$ dan air $92,6 \%$. Selulosa adalah polimer linier yang terdiri dari 300 sampai 15000 glukosa. Material padatan berpori memiliki kemampuan dalam menyerap suatu bahan (Anthony, 1992).

Material akustik digunakan untuk mengurangi kebisingan yang bersifat berpori, resonator dan panel. Material akustik adalah suatu bahan yang dapat menyerap energi suara yang datang dari sumber bunyi.

Penyerapan bunyi dinyatakan dalam koefisien absorbsi bunyi $(\alpha)$, dimana nilai 0 menyatakan tidak adanya energi bunyi yang diserap dan angka 1 menunjukkan serapan yang sempurna. Nilai koefisien absorbsi bunyi tidak tetap tetapi bervariasi berdasarkan frekuensi bunyi dan sudut datangnya gelombang bunyi (Doelle, 1986). 
Koefisien absorbsi bunyi diuji dengan menggunakan metode tabung impedansi dengan memvariasikan komposisi serat dengan matriks. Serat dan matriks merupakan parameter dalam menentukan koefisien absorbsi.

Metode tabung impedansi merupakan salah satu cara untuk mengukur absorbsi bahan terhadap gelombang bunyi. Metode tabung impedansi digunakan untuk sampel berukuran kecil karena menggunakan rasio gelombang tegak. Metode ini digunakan karena cocok untuk pekerjaan teoritik.

Koefisien absorbsi bunyi $(\alpha)$ dihitung dengan menggunakan Persamaan (1) sebagai berikut (Beranek, 1993)

$$
\alpha=1-\left(\frac{S W R-1}{S W R+1}\right)^{2}
$$

dimana,

$$
S W R=\frac{A+B}{A-B}
$$

$S W R=$ Rasio Gelombang Tegak

Impedansi akustik (Z) dapat dihitung dengan menggunakan Persamaan (3) sebagai berikut ini :

$$
Z_{S}=\operatorname{coth}\left(\Psi_{1}+i \Psi_{2}\right) \rho c
$$

dimana,

$$
\begin{aligned}
& \Psi_{1}=\operatorname{coth}^{-1}\left(\log _{10}(S W R / 20)\right) \\
& \Psi_{2}=\pi\left(\frac{1}{2}-\frac{d_{1}}{d_{2}}\right)
\end{aligned}
$$

Densitas $(\rho)$ material akustik dapat dihitung dengan menggunakan Persamaan (4) sebagai berikut ini :

$$
\rho=\frac{m}{V}
$$

\section{METODE}

Pembuatan komposit dibuat dengan memvariasikan campuran serat dan matriks PVAc. Langkah pembuatan komposit serat yaitu dengan mengeringkan eceng gondok dibawah terik matahari selama \pm 10 hari dalam waktu 4 jam per hari dan eceng gondok di oven selama 30 menit dengan suhu $90^{\circ} \mathrm{C}$. Serat yang telah kering digiling dengan menggunakan mesin penepung dengan ukuran $(0,6-4) \mathrm{mm}$. Komposit serat dicetak menggunakan alat hidrolik dengan tekanan 2 ton. Sampel diukur nilai koefisien absorbsinya menggunakan metode tabung impedansi. Data diambil dengan cara mengukur amplitudo tekanan minimum $(A-B)$ dan amplitudo tekanan maksimum $(A+B)$. Mikrofon digeser dari sampel sehingga menunjukkan jarak amplitudo minimum pertama $\left(d_{1}\right)$. Mikrofon digeser lagi sehingga outputnya menampilkan jarak amplitudo tekanan minimum kedua $\left(d_{2}\right)$ 


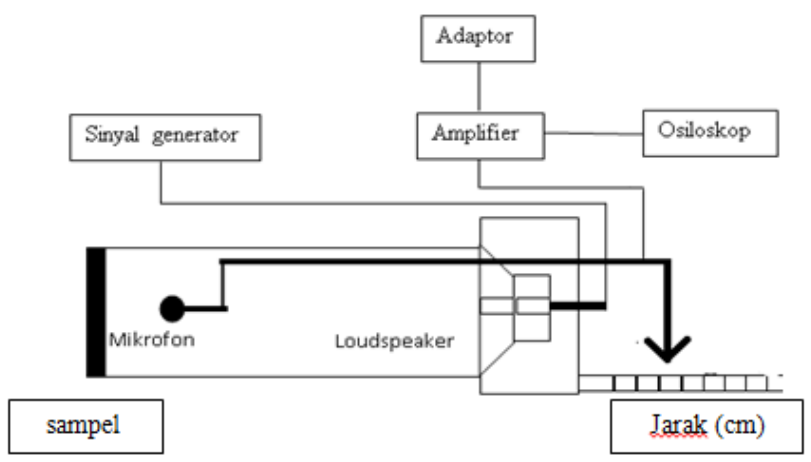

Gambar 1. Skema rangkaian tabung impedansi

\section{HASIL DAN DISKUSI}

\subsection{Nilai Koefisien Absorbsi Bunyi}

Nilai koefisien absorbsi bunyi material akustik serat eceng gondok didapatkan hasil pengujian tampak bahwa terjadi perubahan akibat variasi-variasi diberikan nilai amplitudo tekanan maksimum dan amplitudo tekanan minimum dengan rentang frekuensi $400 \mathrm{~Hz}, 800 \mathrm{~Hz}, 1600 \mathrm{~Hz}, 3200 \mathrm{~Hz}$ dan $6400 \mathrm{~Hz}$.

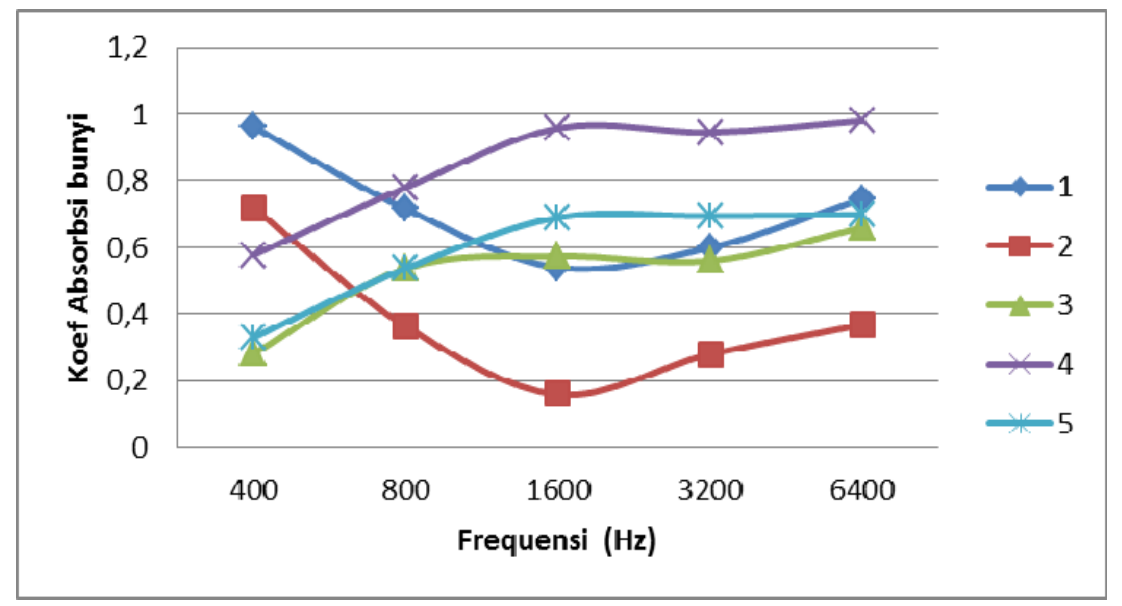

Gambar 2. Hubungan nilai koefisien absorbsi bunyi terhadap frekuensi

Hasil menunjukkan pada sampel 1 dan sampel 2 frekuensi $400 \mathrm{~Hz}-1600 \mathrm{~Hz}$ mengalami penurunan koefisien absorbsi bunyi, kemudian pada frekuensi $1600 \mathrm{~Hz}-6400 \mathrm{~Hz}$ koefisien absorbsi bunyi meningkat. Sampel 3 pada frekuensi $400 \mathrm{~Hz}-1600 \mathrm{~Hz}$ meningkat koefisien absorbsi bunyi. Sampel 4 dan 5 nilai koefisien absorbsi bunyi lebih tinggi dan konstan nilainya daripada sampel lain untuk frekuensi $1600 \mathrm{~Hz}-3200 \mathrm{~Hz}$. Koefisien absorbsi bunyi naik karena material tersebut memiliki pori-pori sehingga gelombang bunyi mudah masuk dan diserap dalam material akustik, sedangkan koefisien absorbsi bunyi turun disebabkan karena material padat sehingga gelombang bunyi akan sulit masuk kedalam material akustik. 


\subsection{Nilai Impedansi (Z) Material Akustik}

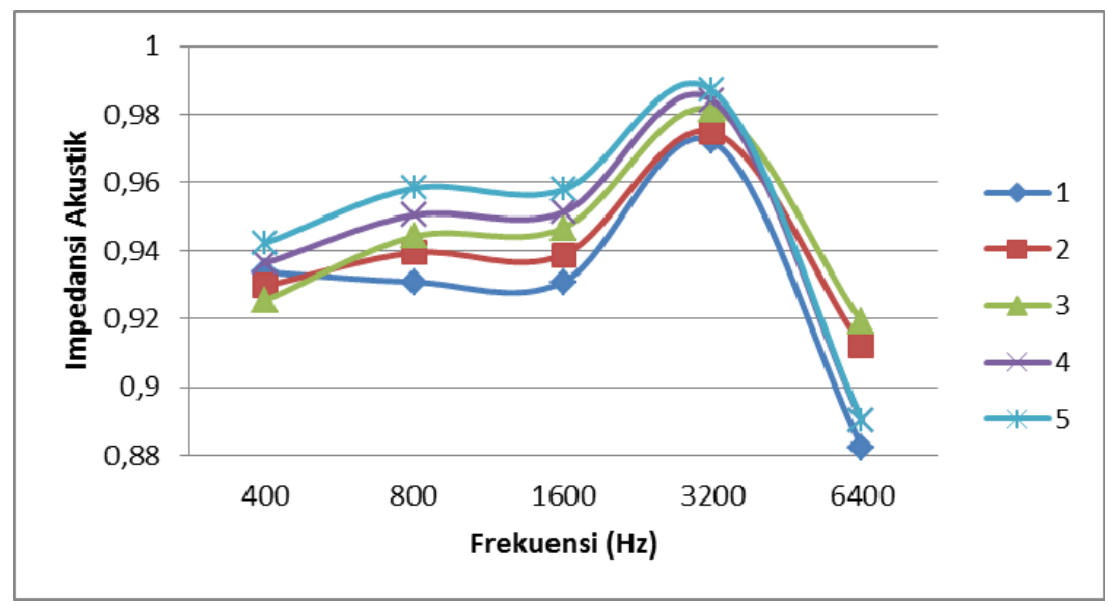

Gambar 3. Hubungan nilai impedansi akustik terhadap frekuensi

Hasil pengujian menunjukkan frekuensi $800 \mathrm{~Hz}, 1600 \mathrm{~Hz}$ dan $3200 \mathrm{~Hz}$ semakin besar komposisi serat, maka semakin tinggi nilai impedansi akustik. Frekuensi $400 \mathrm{~Hz}$ dan $6400 \mathrm{~Hz}$ menunjukkan penurunan nilai impedansi akustik. Nilai impedansi akustik tertinggi yakni $0,9869 \mathrm{~kg} / \mathrm{m}^{2} \mathrm{~s}$ dengan frekuensi $6400 \mathrm{~Hz}$, sedangkan impedansi akustik terendah dengan nilai $0,8825 \mathrm{~kg} / \mathrm{m}^{2} \mathrm{~s}$.

Nilai impedansi akustik juga berpengaruh terhadap koefisien absorbsi bunyi. Bahan material yang kerapatannya tinggi, energi bunyi akan sulit menembus material tersebut karena porositasnya kecil, kecepatan bunyi kecil dan impedansinya besar sehingga bunyi lebih banyak dipantulkan daripada diserap.

\subsection{Penambahan Massa Serat}

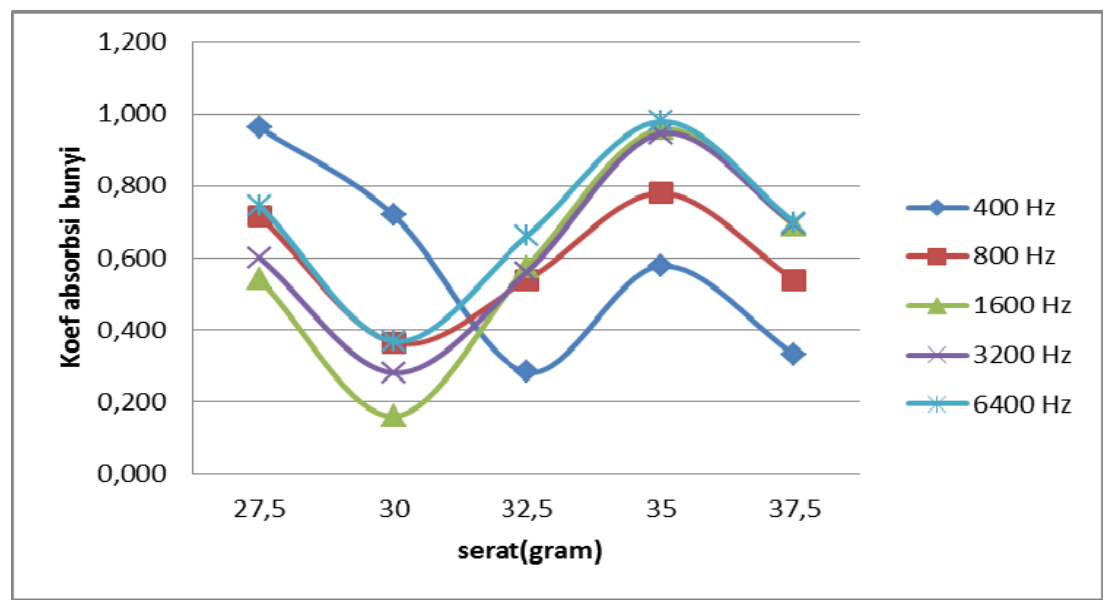

Gambar 4. Hubungan koefisien absorbsi bunyi terhadap penambahan serat

Hasil pengujian menunjukkan bahwa penambahan serat sebanyak 2,5 gr pada pembuatan komposit menyebabkan nilai koefisien absorbsi bunyi menjadi tidak stabil kenaikkannya. Frekuensi $800 \mathrm{~Hz}, 1600 \mathrm{~Hz}, 3200 \mathrm{~Hz}$ dan $6400 \mathrm{~Hz}$ dengan massa serat sebanyak 27,5 - 30 gr dan 35 - 37,5 gr pada mengalami penurunan nilai koefisien absorbsi bunyi, sedangkan massa serat sebanyak $30-32,5$ gr dan 32,5 - 35 gr terjadi kenaikan koefisien absorbsi 
bunyi. Frekuensi $400 \mathrm{~Hz}$ menunjukkan bahwa massa serat sebanyak 27,5 - 30 gr terjadi penurunan secara linier akan tetapi massa serat 30 - 32,5 gr kurvanya landai.

Penambahan serat eceng gondok menyebabkan koefisien absorbsi bunyi tidak konstan disebabkan karena saat membuat komposit, tekanan yang diberikan secara manual tidak dapat di kontrol sehingga antara komposit satu dengan komposit lainnya memiliki nilai densitas bahan masing-masing sampel yang berbeda berdasarkan kuat tekan yang diberikan

\subsection{Densitas}

Tabel 1. Nilai Densitas dari Serat Alam Eceng Gondok

\begin{tabular}{|c|c|c|c|c|c|}
\hline Sampel & $\begin{array}{c}\text { Massa } \\
(\mathrm{gr})\end{array}$ & $\begin{array}{c}\text { Jari-jari } \\
(\mathrm{cm})\end{array}$ & $\begin{array}{c}\text { Volume } \\
\left(\mathrm{cm}^{3}\right)\end{array}$ & $\begin{array}{c}\text { Densitas } \\
\left(\mathrm{g} / \mathrm{cm}^{3}\right)\end{array}$ & $\begin{array}{c}\text { Koefisien } \\
\text { Absorbsi Bunyi } \\
(6400 \mathrm{~Hz})\end{array}$ \\
\hline 1 & 24,7 & 3,80 & 36,3 & 0,68 & 0,75 \\
\hline 2 & 35,8 & 3,95 & 39,2 & 0,91 & 0,37 \\
\hline 3 & 32,8 & 3,85 & 37,2 & 0,88 & 0,66 \\
\hline 4 & 25,7 & 3,90 & 38,2 & 0,67 & 0,98 \\
\hline 5 & 33,3 & 3,95 & 39,2 & 0,84 & 0,70 \\
\hline
\end{tabular}

Sampel 4 mempunyai densitas paling rendah yaitu 0,67 dengan koefisien absorbsi bunyi paling tinggi yaitu 0,98 . Hal ini disebabkan sebahagian besar gelombang diserap oleh material akustik.

Densitas yang rendah cendrung memiliki banyak rongga atau porositas yang banyak, sehingga bunyi lebih mudah masuk ke material dan diserap langsung oleh sampel.

\section{KESIMPULAN}

Koefisien absorbsi bunyi tertinggi dengan nilai 0,98 pada frekuensi $6400 \mathrm{~Hz}$ sampel 4 komposisi serat $35,0 \mathrm{~g}$ dan matriks $27,5 \mathrm{~g}$, sedangkan koefisien absorbsi bunyi terendah yakni 0,16 pada frekuensi $1600 \mathrm{~Hz}$ sampel 2 komposisi serat 30,0 g dan matriks 32,5 g. Nilai impedansi akustik tertinggi yakni $0,9869 \mathrm{~kg} / \mathrm{m}^{2} \mathrm{~s}$ pada frekuensi $6400 \mathrm{~Hz}$, sedangkan nilai impedansi akustik terendah yakni $0,8825 \mathrm{~kg} / \mathrm{m}^{2}$ s pada frekuensi $400 \mathrm{~Hz}$. Densitas terendah $0,67 \mathrm{~g} / \mathrm{cm}^{3}$ dengan nilai koefisien absorbsi bunyi 0,98 , sedangkan densitas tertinggi yakni $0,91 \mathrm{~g} / \mathrm{cm}^{3}$ dengan nilai koefisien absorbsi bunyi 0,37 pada frekuensi $6400 \mathrm{~Hz}$.

\section{DAFTAR PUSTAKA}

1. Anthony, W.C., 1992, Pengantar Kimia Organik dan Hayati, Michael B., Matta, Erlangga, Jakarta.

2. Beranek, L.L., 1993, Acoustics, Acoustical Society of America, Woodbridge, New York.

3. Doelle, L.L., 1986, Akustik Lingkungan, Edisi Pertama, Erlangga, Jakarta.

4. Gibson, F.R., 1984, Principles of Composite material Mechanis, International Edition, McGraw-Hill Inc, New York.

5. Na Y, L. J., dan Cho, G., 2007, Sound Absorption Coefficients of Micro-fiber Fabrics by Reverberation Room Method, Textile Research Journal, Vol.5, No.1, hal 330-335. 